\title{
Predicting Internet Banking Effectiveness using Artificial Model
}

\author{
Ala Aldeen Al-Janabi \\ Ahmed Bin Mohammed Military College, Doha, Qatar
}

\begin{abstract}
This research aims at building a prediction model to predict the effectiveness of internet banking (IB) in Qatar. The proposed model employs the aspect of hybrid approach through using the regression and neural network models. This study is one of the fewest to evaluate the effectiveness of IB through adopting two data mining approaches including regression and neural networks. The regression analysis is used to optimize and minimize the input dataset metrics through excluding the insignificant attributes. The study builds a dataset of 250 records of internet banking quality metrics where each instance includes 8 metrics. Moreover, the study uses the rapidminer application in building and validating the proposed prediction model. The results analysis indicates that the proposed model predicts the $88.5 \%$ of IB effectiveness, and the input attributes influence the customer satisfaction. Also, the results show the prediction model has correctly predict $68 \%$ of the test dataset of 50 records using neural networks without regression optimization. However, after employment of regression, the prediction accuracy of satisfaction improved by $12 \%$ (i.e. $78 \%$ ). Finally, it is recommended to test the proposed model in the prediction in other online services such as e-commerce.
\end{abstract}

Keywords-Artificial Neural Network (ANN); internet banking (IB); Artificial Intelligence (AI); e-banking effectiveness; regression model; rapidminer

\section{INTRODUCTION}

The employment of various technological tools in banking industry can be classified under the umbrella of Electronic Banking (e-banking), and thus, e-banking can be defined as a variety of e-channels for carrying on the banking transactions through various technologies such as telephone, Internet, TV, computer and mobile [1]. Darwish and Lakhtaria [2] indicated that the e-banking transactions and services mainly depend on the information exchange between customers and banking services providers by means of technological methods without face-to-face interaction. Therefore, the technology growth has transformed the method banks deliver the services to customers [3]. The internet technology features add many advantages to e-banking such as fast financial transaction and low service cost, and thus, the Internet technology has a significant impact on e-banking [4]. In Internet banking, the online transaction platform play an important role in supporting several services such as online payment, online shopping, and internet stock trading [5], [6].

Despite of the internet banking advantages such as fast transaction, there are still many customers are not satisfied with the online banking services [7], [8]. Therefore, it is important to develop an assessment model to measure the effectiveness of internet banking in terms of customer satisfaction. Several researches have explored the assessment of e-banking services quality using data mining methods such as neural, however, especially in Qatar; few have investigated the prediction of internet banking effectiveness in a comprehensive manner through a 2-stage model using prediction and neural models.

So, this research fills the gap in empirical studies because it tests the effect of the inclusion of two prediction model on the accuracy of e-banking evaluation. Additionally, it addresses the gap in literature the prediction using new dataset developed theoretical model derived from two models including TAM and D\&M2003.

\section{LITERATURE REVIEW}

This section explains the theoretical foundations of ebanking in addition to the study variables derived from D\& M 2003 including the quality factors, customer satisfaction and usefulness.

1) e-Banking: In the financial industry, the Electronic Finance (e-finance) has recently become as a common trend where the e-finance denotes the use of electronic means and communication to provide the financial services including ebanking, internet banking (IB), electronic trading, and electronic payment [9]. Kumbhar [10] indicated that e-banking often denoted the online banking and some researchers explained that e-banking services has been developed and expanded because most of banking services are conducted via electronic channels such as ATM [11]. The e-banking term is used interchangeably when individuals talk about electronic financial banking services such as: net-banking, Web-banking and phone banking [12].

2) Internet banking: The internet banking (IB) is to perform the financial transactions without need for physical contact and it is considered as of the examples in employing technology in banking sector. Moreover, the internet banking is one of the essential parts of e-banking industry [13]. Many researchers identified the internet banking as internet portal that enable the customers to carry out various types of banking transactions and services using the internet [14].

3) e-Service Quality: It is pointed by many researchers that service quality is an essential measure for customer satisfaction where it has a significant impact on customer satisfaction and company financial performance as a whole [15], [16].

Service quality is considered as the most common topic in marketing to date as well as it is the pioneering work of 
Parasuraman whereas the SERVQUAL has developed as a diagnostic tool for evaluating service quality. Marketing researchers (such as, Parasuraman et al., [17]) defined the service quality as the extent to which the service meets the expectations of customers. Service quality is also defined as the variation in customers' expectations for service performance before and after receiving service [18].

The service quality measures have been discussed by many researchers (such as, Petter et al. [19], Wang et al. [20], Alhendawi et al. [21]) SERVQUAL was developed as an assessment tool to measure service quality and it is widely used within IS Literature in order to measure the gap between customer's expectations and experience. This instrument (i.e. SERVQUAL) have basically consisted of ten measures including tangible, reliability, competence, courtesy, responsiveness, access, credibility, communication, security and knowledge of customers. Later, the researchers Parasuraman et al. [17] filtered these measures and minimized them using factor analysis into five dimensions: tangibles, reliability, responsiveness, assurance and empathy in order to measure the service quality from the customers' point of view. Table I reveals the meaning of service quality’s dimensions.

4) Customer satisfaction: Many researchers mentioned that customer satisfaction is considered as one of the critical issues for service organizations [22], [23], and also, it is highly important for measuring the quality of bank services [24], [25]. Based on review, it is obvious that the quality improvement has a positive impact on the customer satisfaction level which in turn positively influence the bank profitability [26]. Additionally, it is pointed by several researchers that service quality is the most important factor influencing customer satisfaction [27].

5) Internet banking usefulness: In the Web systems, the effective use of information for a given purpose [28]. However, the internet banking usefulness can be defined as the extent to which providers can ease the online services such as the financial transactions, online payment and others through adoption of new technological tools [29].

6) Interactivity: For Internet banking, interactivity can be defined as the degree to which the internet banking provides an interactive communication with customers [30], [31].

7) Security: The internet banking security means the extent to which the exchanged data is secured or protected from threats [32].

8) Ease of use: The ease of use can be expressed as one of Web system features where the users can use the system easily without paying much effort [33]. In Internet banking, ease of use indicates the user view of how easy to learn and use the online banking operations [34]. Thus, decision makers and mangers should keep attention to the following metrics: bank services quality, usefulness, security, ease of use, and interactivity, as they are essentials for determining and improving the customer satisfaction. The following section represents the theoretical model which shows the relationships between the input and output data.
TABLE I. SERVICE QUALITY DIMENSIONS (ADAPTED FROM PARASURAMAN ET AL. [17])

\begin{tabular}{|l|l|l|}
\hline No. & Dimension & Meaning \\
\hline 1 & Tangible & $\begin{array}{l}\text { Physical facilities, equipment and appearance } \\
\text { of personnel }\end{array}$ \\
\hline 2 & Reliability & $\begin{array}{l}\text { Ability to perform the promised service } \\
\text { dependably and accurately }\end{array}$ \\
\hline 3 & Responsiveness & $\begin{array}{l}\text { Willingness to help customers and provide } \\
\text { prompt service. }\end{array}$ \\
\hline 4 & Assurance & $\begin{array}{l}\text { Knowledge and courtesy of employees and } \\
\text { their ability to inspire trust and confidence. }\end{array}$ \\
\hline 5 & Empathy & $\begin{array}{l}\text { Caring, individualized attention the firm } \\
\text { provides its customers. }\end{array}$ \\
\hline
\end{tabular}

\section{THEORETICAL FRAMEWORK}

Based on the literature review (Alhendawi et al. [35], [36], Petter et al., [37], Delone \& Mclean [38]), it is essential to use the quality factors such as service quality, security, privacy and usefulness as a success factors to identify the e-Banking system effectiveness in terms of customer satisfaction. Moreover, Alhendawi [39] indicated that the AI tools such as artificial neural network and regression can be considered as effective methods in predicting the e-Banking effectiveness as output variable (i.e. customer satisfaction). Accordingly, Fig. 1 reveals the proposed conceptual model used in the prediction of the eBanking effectiveness in terms of customer satisfaction with Internet banking.

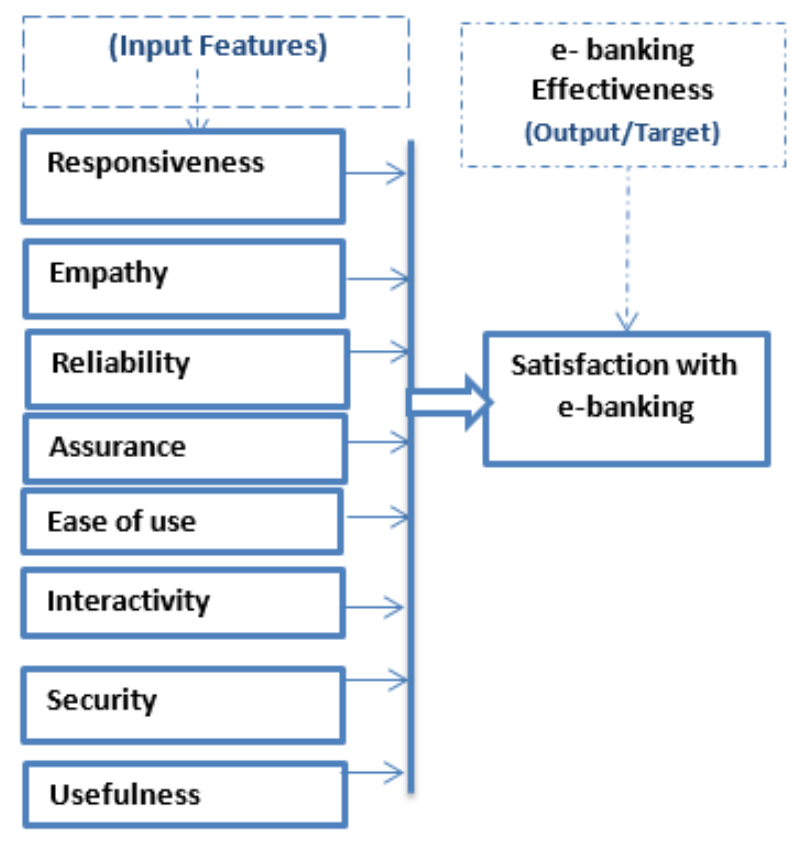

Fig. 1. The Proposed Theoretical Framework. 


\section{RESEARCH METHODOLOGY}

To achieve the research objectives, the authors adopt a methodology of two stages including Dataset and regression stage, and the neural model learning stage. Fig. 2 demonstrates the research methodological steps of the proposed prediction model.

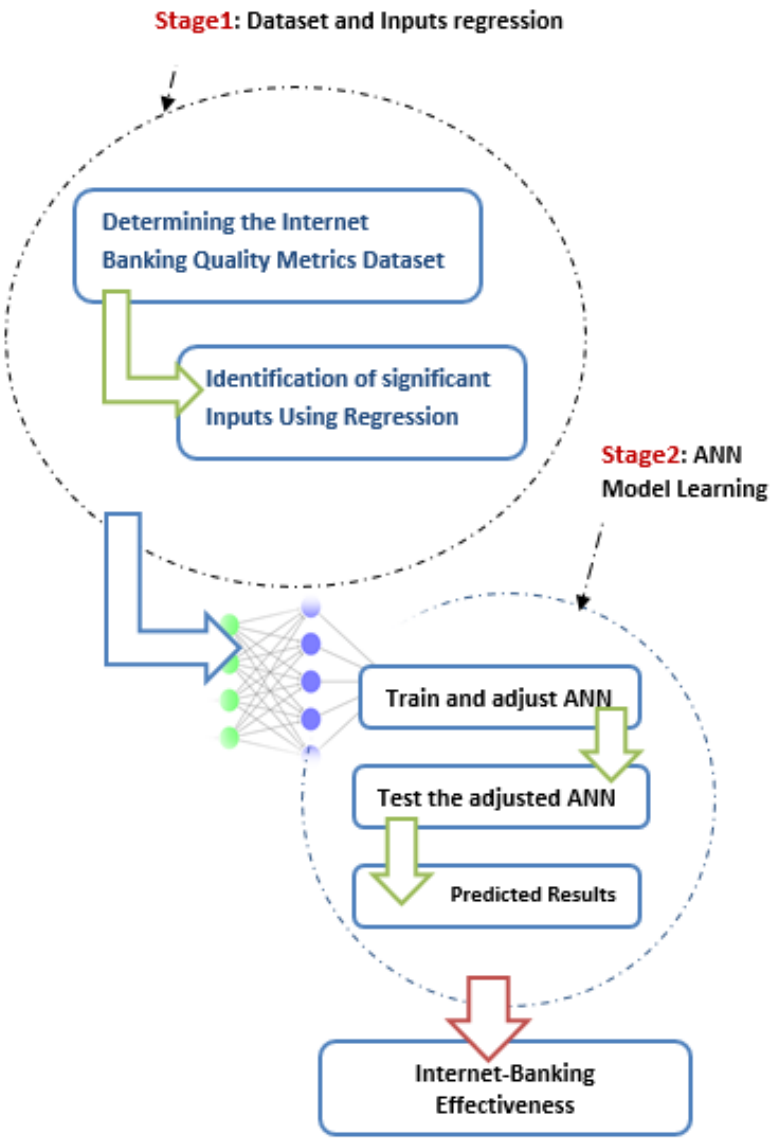

Fig. 2. The Research Methodology.

\section{A. Stage 1: Building Data Set and Optimization}

In this stage, an instrument or questionnaire of nine variables (i.e. factors) was built to include the service quality, security, usefulness, and interactivity, ease of use and satisfaction metrics of the Internet banking.

1) Scaling: A Likert scale of five points is used in order to measure the response of internet banking customers regarding the service quality, interactivity, security, ease of use, usefulness and effectiveness metrics. The metrics are rated by users from strongly agree to strongly disagree.

2) Data collection: The research includes the survey of 250 internet banking customers about their satisfaction with the IB system in Qatar. The survey includes the perceptions of IB users regarding nine metrics: four service quality metrics for responsiveness, reliability, assurance and empathy. The remaining five metrics are interactivity, security, ease of use, usefulness and effectiveness.
3) Reliability: The result of reliability test shows that the reliability of the research scales was relatively high. The value of Cronbach's Alpha of the research scales as a whole was 0.90. Based on Table II, the value of Cronbach's Alpha for the study scales of responsiveness, reliability, assurance and empathy, interactivity, security, ease of use, usefulness and effectiveness were 0.869, 0.918, 0.865, 0.717,0.866, 0.864, $0.730,0.881$ and 0.916 , respectively.

\section{B. Building Dataset}

Based to previous survey study analysis, there are eight causal factors or determinants (responsiveness, reliability, assurance and empathy, interactivity, security, ease of use, and usefulness) and one target (IB effectiveness). Because we have used a Likert scale of 5 points, we consider the mean of customer satisfaction to evaluate whether the IB system is effective or not.

\section{Optimization and Regression}

Based on the proposed method, the optimization is the final step of stage one in which the regression analysis is used to optimize the input attributes. The regression is employed to identify the significant input attributes in order to optimize the prediction process, and thus, the validation test of the proposed model takes into consideration the results of regression analysis as an input for neural networks prediction. The following chart shows the validation steps of the proposed model.

Fig. 3 shows the flowchart of prediction model validation in order to decide regarding the improvement of prediction accuracy of neural networks. It is clearly seen that the proposed model adopt the aspect of mix approach through using a 2-step prediction.

\section{Implemented Neural Network Model}

Based on the mentioned methodology, first, the Rapidminer is used to build the neural network model with eight input metrics and one output target (i.e. IB effectiveness). Fig. 4 shows the neural model of eight inputs metrics with one output.

Second, we applied the regression model to optimize the input dataset based on the significance of its elements, and then, implement the second neural network model with six significant inputs or metrics.

TABLE II. CRONBACH's ALPHA OF STUDY VARIABLES

\begin{tabular}{|l|l|}
\hline Variable & Cronbach's Alpha \\
\hline Responsiveness & 0.869 \\
\hline Reliability & 0.918 \\
\hline Assurance & 0.865 \\
\hline Empathy & 0.717 \\
\hline Interactivity & 0.866 \\
\hline Security & 0.864 \\
\hline Ease of use & 0.730 \\
\hline Usefulness & 0.881 \\
\hline Satisfaction with IB Effectiveness & 0.916 \\
\hline
\end{tabular}




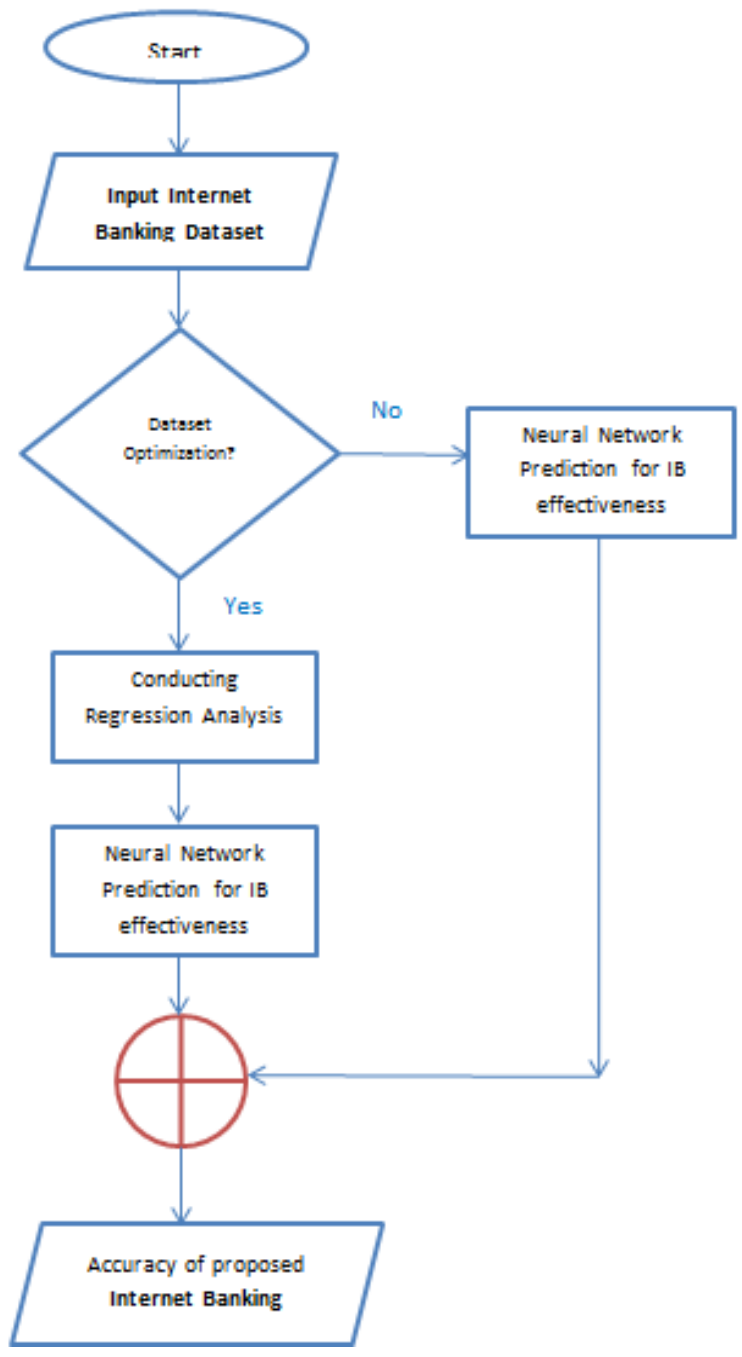

Fig. 3. Validation Process Flowchart.

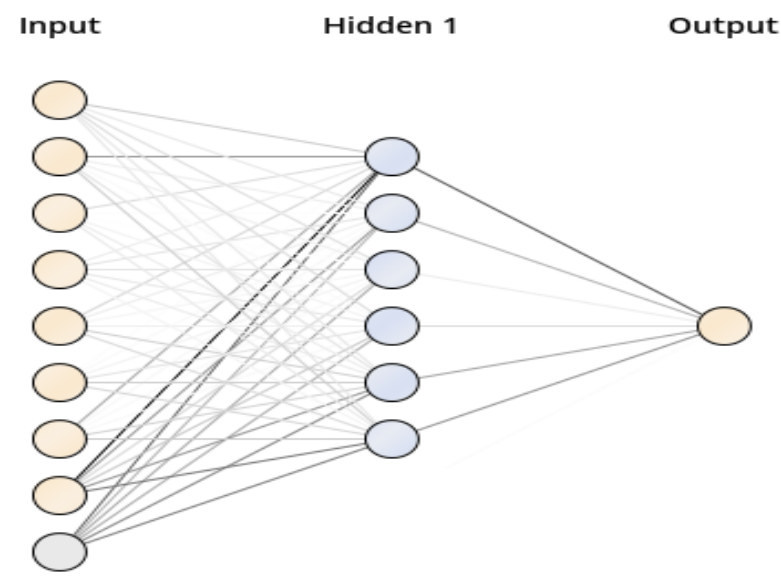

Fig. 4. The Neural Model.

\section{EXPERIMENTAL RESULTS AND FINDINGS}

In this research, the regression and neural network models are employed to build the proposed evaluation model in order to gain the features of the two prediction models.
The proposed ANN model is trained by 250 records where the training data set includes 200 records. For validating and testing purposes, the researcher used 50 records as testing data.

\section{A. Regression}

The regression analysis is used to specify the significant input attributes that contribute to the effectiveness of internet banking in term of customer satisfaction. Table III shows the significance of input attributes including: responsiveness, reliability, assurance, empathy, security, and usefulness, and interactivity, ease of use and satisfaction metrics of the Internet banking.

TABLE III. SIGNIFICANCE OF INPUT METRICS

\begin{tabular}{|l|l|l|l|}
\hline Attribute & Correlation & t stat & $\begin{array}{l}\text { Significance } \\
\text { (P-Value) }\end{array}$ \\
\hline Ease of use & 0.009 & 0.355 & 0.723 \\
\hline Responsiveness & 0.066 & 2.476 & 0.014 \\
\hline Assurance & 0.078 & 2.841 & 0.005 \\
\hline Empathy & -0.029 & -1.333 & 0.183 \\
\hline Reliability & 0.051 & 2.086 & 0.038 \\
\hline Interactivity & 0.096 & 3.492 & 0.011 \\
\hline Usefulness & 0.069 & 2.276 & 0.002 \\
\hline Security & 0.718 & 26.590 & 0.000 \\
\hline$R$ & 0.941 & \multicolumn{2}{|l}{} \\
\hline$R^{2}$ & 0.885 & & \\
\cline { 1 - 2 } & &
\end{tabular}

Also, based on Table III, it is obvious that the input attributes contributes to the effectiveness of internet banking by 0.885 , and therefore, the 8 input attributes contribute to the change in the customer satisfaction by a percentage of $88.5 \%$. Additionally, it is shown that the two metrics ease of use, empathy are insignificant where the P-value for them are 0.723 , 0.183; respectively. Generally, the proposed model metrics is suitable to predict the value of IB effectiveness. The following two subsections show the results of prediction before and after regression optimization.

\section{B. The Predicted Results before Optimization}

Practically, $20 \%$ of data set are used as test dataset (i.e. 50 out of 200 records). The following shows the prediction accuracy of regression and neural models before optimization (i.e. before removing the insignificant attributes).

1) The results of regression prediction: The regression model results show that 32 of 50 effectiveness value can be correctly predicted. Table IV shows the regression prediction statistics where the eight input attribute are counted in the prediction model.

TABLE IV. REGRESSION STATISTICS

\begin{tabular}{|l|l|l|l|l|}
\hline & $\begin{array}{l}\text { Correctly } \\
\text { predicted }\end{array}$ & $\begin{array}{l}\text { Incorrectly } \\
\text { Predicted }\end{array}$ & $\begin{array}{l}\text { Prediction } \\
\text { Success Ratio }\end{array}$ & $\begin{array}{l}\text { No of input } \\
\text { attributes }\end{array}$ \\
\hline Regression & 31 & 19 & $58 \%$ & 8 \\
\hline
\end{tabular}


2) The results of neural networks prediction: The neural model results show that 34 of 50 effectiveness value can be correctly predicted. Table $\mathrm{V}$ shows the neural prediction statistics where the eight input attribute are counted in the prediction model.

TABLE V. The Neural Prediction Statistics With 8 Attributes INPUTS

\begin{tabular}{|l|l|l|l|l|}
\hline & $\begin{array}{l}\text { Correctly } \\
\text { predicted }\end{array}$ & $\begin{array}{l}\text { Incorrectly } \\
\text { Predicted }\end{array}$ & $\begin{array}{l}\text { Prediction } \\
\text { Success Ratio }\end{array}$ & $\begin{array}{l}\text { No of input } \\
\text { attributes }\end{array}$ \\
\hline Neural & 32 & 18 & $60 \%$ & 8 \\
\hline
\end{tabular}

Therefore, there is a slight difference in the prediction success ratios where the success ratios of regression and neural are $58 \%$ and $60 \%$, respectively.

\section{Predicted Results after Optimization}

Based on the results shown in Table III, there are two insignificant attributes or metrics with p-vale $>0.05$. The two input metrics are ease of use and empathy. Based on the proposed prediction model, the significant input attributes resulted from regression are used as inputs for neural prediction. Thus, above two metrics are removed from the input attributes, and six significant attributes are used in the new neural prediction model.

Fig. 5 shows the neural network structure after optimizing the input attributes to become six attributes. Table V shows the neural prediction statistics where six-significant input attributes are counted in the prediction model.

Based on Table VI, the success prediction ratio after regression optimization (i.e. using 6 significant inputs) is $78 \%$ and this means the prediction is improved by $18 \%$. This means after optimization of inputs, neural model succeeds in predicting 39 out 50 data elements which are obviously seen in Fig. 6.

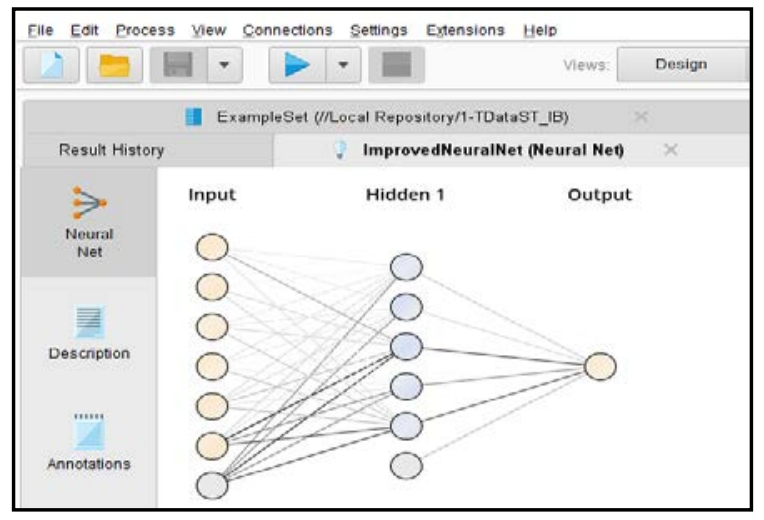

Fig. 5. The Neural Network after Regression.

TABLE VI. The Neural Prediction Statistics with 6 Attributes INPUTS

\begin{tabular}{|l|l|l|l|l|}
\hline & $\begin{array}{l}\text { Correctly } \\
\text { predicted }\end{array}$ & $\begin{array}{l}\text { Incorrectly } \\
\text { Predicted }\end{array}$ & $\begin{array}{l}\text { Prediction } \\
\text { Success Ratio }\end{array}$ & $\begin{array}{l}\text { No of input } \\
\text { attributes }\end{array}$ \\
\hline Neural & 39 & 11 & $78 \%$ & 6 \\
\hline
\end{tabular}

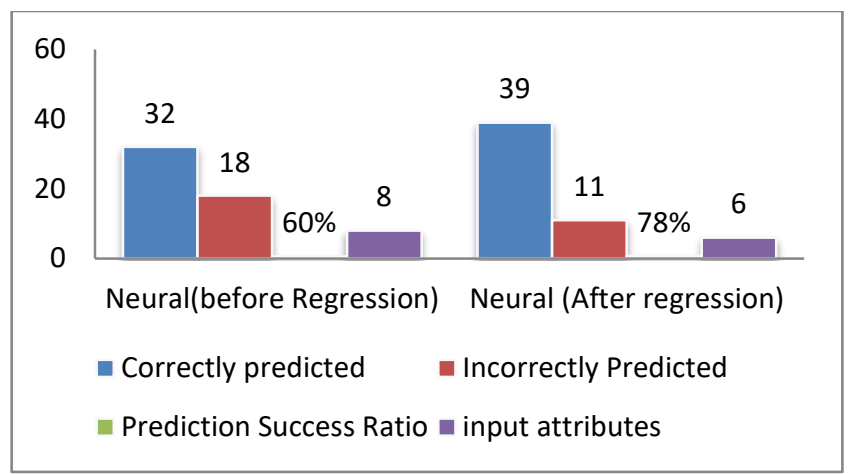

Fig. 6. The Success Rations of Prediction.

Table VII shows the success status of the tested 50 cases where 1 denotes that the prediction of customer satisfaction succeeds, however, 0 means the proposed model fails to predict the satisfaction with Internet banking.

The following charts in Fig. 7, 8, 9, 10, 11 and 12 demonstrate the relationships between the internet banking effectiveness in terms of customer satisfaction and its predictors including responsiveness, reliability, assurance, empathy, interactivity, usefulness, ease of use and security.

\section{The Relationships between Input Attributes and Predicted Customer Satisfaction}

The x-axis represents the customer satisfaction attribute. In particular, Fig. 7 reveals that the attribute of responsiveness significantly influences the customer satisfaction with Internet banking.

TABLE VII. The Status of Cases Prediction

\begin{tabular}{|l|l|l|l|l|l|}
\hline Case ID & Status & Case ID & Status & Case ID & Status \\
\hline C1 & 1 & C18 & 1 & C35 & 1 \\
\hline C2 & 1 & C19 & 1 & C36 & 1 \\
\hline C3 & 1 & C20 & 1 & C37 & 0 \\
\hline C4 & 0 & C21 & 0 & C38 & 1 \\
\hline C5 & 1 & C22 & 1 & C39 & 1 \\
\hline C6 & 0 & C23 & 1 & C40 & 1 \\
\hline C7 & 1 & C24 & 1 & C41 & 0 \\
\hline C8 & 1 & C25 & 1 & C42 & 1 \\
\hline C9 & 0 & C26 & 1 & $\mathbf{C 4 3}$ & 1 \\
\hline C10 & 1 & C27 & 1 & C44 & 1 \\
\hline C11 & 1 & C28 & 1 & C45 & 1 \\
\hline C12 & 1 & C29 & 1 & C46 & 1 \\
\hline C13 & 1 & C30 & 1 & $\mathbf{C 4 7}$ & 0 \\
\hline C14 & 0 & C31 & 0 & C48 & 0 \\
\hline C15 & 1 & C32 & 1 & C49 & 0 \\
\hline C16 & 1 & C33 & 1 & C50 & 1 \\
\hline C17 & 1 & C34 & 1 & & \\
\hline
\end{tabular}




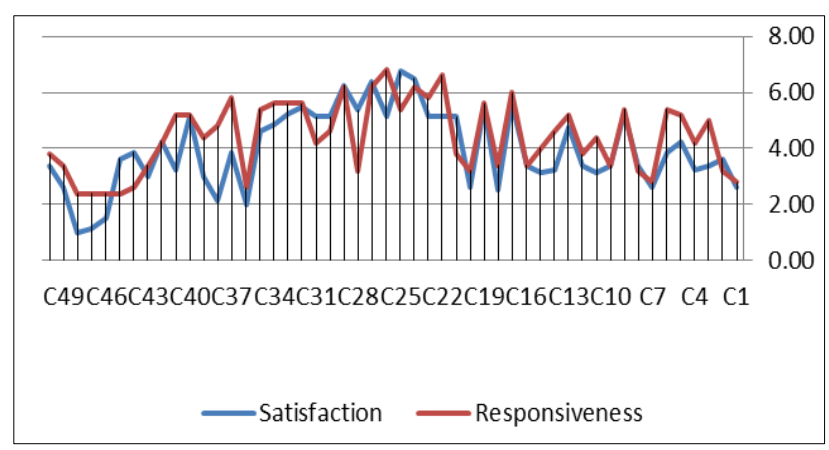

Fig. 7. The Impact of Responsiveness on Internet Banking Effectiveness.

Also, Fig. 8, 9, 10, 11 and 12 demonstrate that the remaining five attributes follow the same pattern, i.e. as the reliability, assurance, interactivity, security and usefulness attributes increased the customer satisfaction increased.

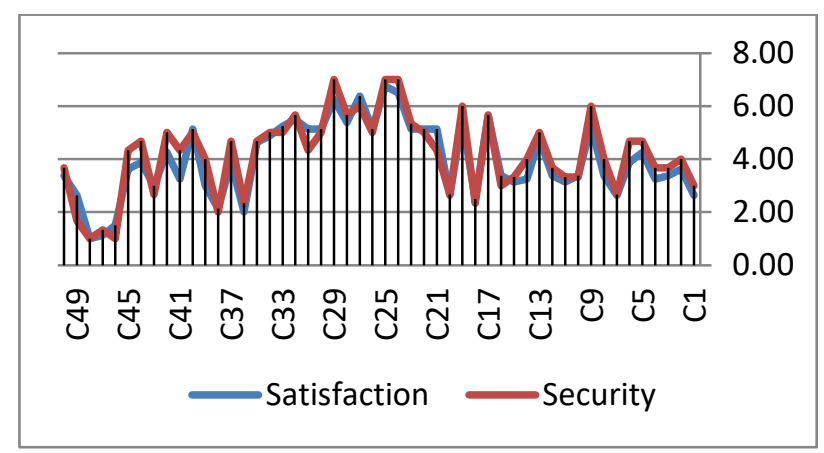

Fig. 8. The Impact of Security on Internet Banking Effectiveness.

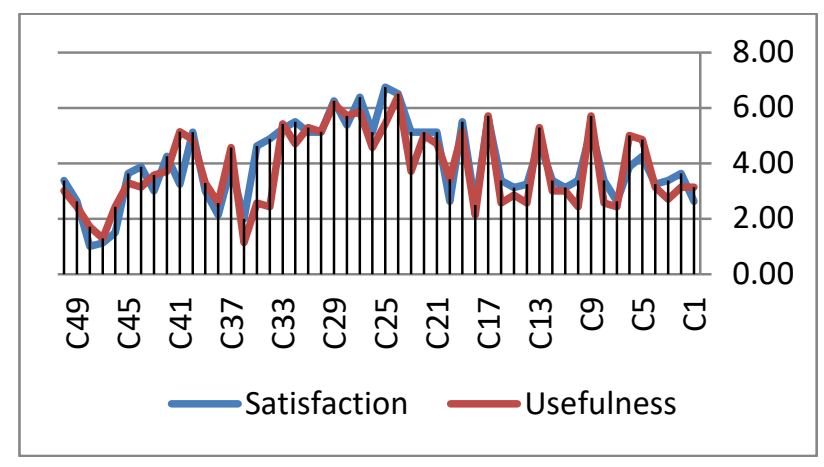

Fig. 9. The Impact of usefulness on Customer Satisfaction with IB.

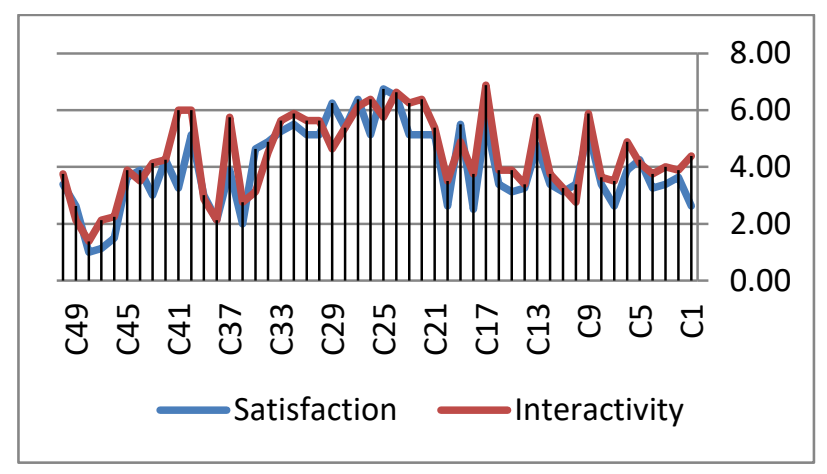

Fig. 10. The Impact of Interactivity on Customer Satisfaction.

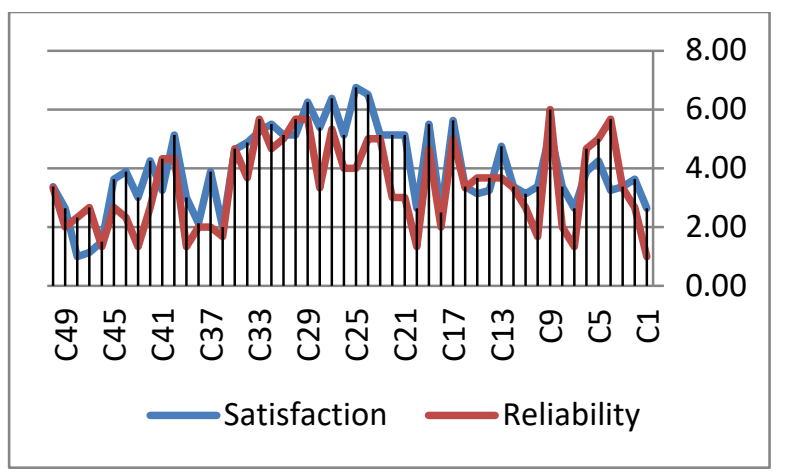

Fig. 11. The Impact of Reliability on Customer Satisfaction with IB.

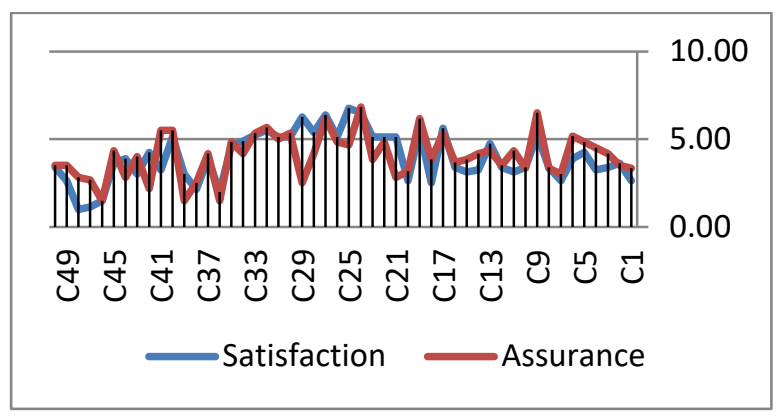

Fig. 12. The Impact of Assurance on Customer Satisfaction with IB.

Based on the correlation analysis of test data set, it is found the six attributes have a relatively high correlations with customer satisfaction with IB (i.e. correlation coefficient $r$ $>0.5$ ). The highest four correlations are for the attributes: security, assurance, responsiveness, and usefulness (0.919, 0.696, 0.665 and 0.657 ), then the last two correlations are for interactivity and reliability (0.596 and 0.563$)$.

\section{CONCLUSION AND DISCUSSION}

This research aims at evaluating the internet banking (IB) effectiveness based on the eight quality attributes: responsiveness, reliability, assurance, Empathy, interactivity, security, usefulness and ease of use. The questionnaire is used for gathering the dataset attributes regarding the internet banking services in Qatar. The dataset has 250 records divided into training and testing datasets by the percentages $80 \%$ for training and $20 \%$ for testing (i.e. 50 records).

The collected records were used as input dataset for regression model in order to optimize and find the significant input attributes, and then, the optimized 6 attributes are used to train the neural network model. Practically, a new hybrid approach using artificial neural network was proposed for determining the relationships between research variables. In this research, the rapidminer software is used to build the neural model using 8 inputs and one target (IB effectiveness).

The accuracy of the proposed model has been done by using a dataset of 50 records. The obtained results provided an evidence that the results of the proposed prediction model are suitable for handling the nonlinear relationships. Moreover, as the proposed ANN model correctly predicted 39 target values out of 50 (i.e. correct prediction percentage $=78 \%$ ), based on the results (i.e. improvement in prediction by $18 \%$ ), the neural 
network is useful in predicting the effectiveness of online services. Furthermore, it is found that the input attributes including responsiveness, reliability, assurance, empathy, interactivity, usefulness, ease of use, and security influence the internet banking effectiveness which is measured in terms of satisfaction. This research is one of the fewest to consider the eight input attributes as IB effectiveness predictors. Second, the research helps the decision makers to decide regarding the improvement of their online services, which in turn increase the customer satisfaction with online transactions such as internet banking services.

One of the major limitations of the research was that the proposed prediction model did not consider all customer satisfaction predictors. Second, the accuracy of prediction is reasonable (i.e. 78\%), and thus, more improvement can be applied on the proposed intelligent model through to the other remaining quality attributes such as Technology Acceptance Model (TAM) attributes as predictors in the upcoming research.

\section{REFERENCES}

[1] Olga. "Can e-banking services be profitable?." University of Tartu Economics and Business Administration Working Paper 30-2004 (2004).

[2] Darwish, Ashraf, and Kamaljit I. Lakhtaria. "The impact of the new Web 2.0 technologies in communication, development, and revolutions of societies." Journal of advances in information technology 2.4 (2011), pp. 204-216.

[3] Abd El Kader, Nermine. E-customer relationship management readiness in the banking industry: the case of Egypt. Diss. Middlesex University, 2012.

[4] Bauer, Hans H., Maik Hammerschmidt, and Tomas Falk. "Measuring the quality of e-banking portals." International journal of bank marketing (2005).

[5] Blut, Markus. "E-service quality: development of a hierarchical model." Journal of Retailing 92.4 (2016), pp. 500-517.

[6] Bell, Emma, Alan Bryman, and Bill Harley. Business research methods. Oxford university press, 2018.

[7] Chin, Wynne W. "Commentary: Issues and opinion on structural equation modeling." (1998), JSTOR.

[8] Cohen, Jacob. Statistical power analysis for the behavioral sciences. Academic press, 2013.

[9] Ziaee, Morteza. "Research on the internet and check the status of ebanking in Iran." International Letters of Social and Humanistic Sciences 10 (2014), pp. 172-180

[10] Kumbhar, Vijay M. "Determinants of internet banking adoption: an Empirical evidences from Indian banking." Indian Journal of Commerce and Management Studies 2.4 (2011), pp.15-25.

[11] Hussain, Zahoor, et al. "E-banking challenges in Pakistan: An empirical study." Journal of Computer and Communications 5.2 (2017), pp. 1-6.

[12] Shanka, Mesay Sata. "Bank service quality, customer satisfaction and loyalty in Ethiopian banking sector." Journal of Business Administration and Management Sciences Research 1.1 (2012), pp. 1-9.

[13] Oluwatolani, Oluwagbemi, Abah Joshua, and Achimugu Philip. "The impact of Information Technology in Nigeria's banking industry." arXiv preprint arXiv:1108.1153 (2011).

[14] Firdous, Sadaf, and Rahela Farooqi. "Impact of internet banking service quality on customer satisfaction." The Journal of Internet Banking and Commerce 22.1 (2017), pp. 1-17

[15] Kadir, Hazlina Abdul, Nasim Rahmani, and Reza Masinaei. "Impacts of service quality on customer satisfaction: study of online banking and ATM services in Malaysia." International Journal of Trade, Economics and Finance 2.1 (2011).

[16] ASHIQULLAH, S. "A relational study on automated service quality, customer satisfaction and financial performance in the context of Bank
Asia Ltd available at: ww. sb. iub. edu. bd/internship/summer2 006/0320454. pdf (accessed January 28, 2016)." Summer internship report submitted to IUB University, Bashundhara (2006).

[17] Parasuraman, A., Valarie A. Zeithaml, and L. Berry. "SERVQUAL: A multiple-item scale for measuring consumer perceptions of service quality." 198864.1 (1988), pp. 12-40.

[18] Asubonteng, Patrick, Karl J. McCleary, and John E. Swan. "SERVQUAL revisited: a critical review of service quality." Journal of Services marketing (1996).

[19] Petter, Stacie, William DeLone, and Ephraim R. McLean. "The past, present, and future of "IS success"." Journal of the Association for Information Systems 13.5 (2012).

[20] Wang, Yi-Shun, and Yi-Wen Liao. "The conceptualization and measurement of m-commerce user satisfaction." Computers in human behavior 23.1 (2007), pp. 381-398.

[21] Alhendawi,K., \& Al-Janabi, A.” An Intelligent Neural Model for Assessing Web Systems Performance". International Journal of advanced trends in computer science and engineering, 2020, pp.18541860

[22] Alhendawi, Kamal Mohammed, and Ahmad Suhaimi Baharudin. "The impact of interaction quality factors on the effectiveness of Web-based information system: the mediating role of user satisfaction." Cognition, technology \& work 16.4 (2014), pp. 451-465.

[23] Adepoju, Solomon Adelowo, et al. "Multi-Criteria Decision-Making Based Approaches in Website Quality and Usability Evaluation: A Systematic Review." Journal of Information and Communication Technology 19.3 (2020), pp.399-436.

[24] Maranga, Wilfred Nyanusi. Customer Perception of Electronic Banking Service Quality Provided By KCB Bank Kenya Ltd: A Case Study of UN Gigiri Branch. Diss. United States International University-Africa, 2017.

[25] Saha, Sampa, and Zinnatun Nesa. "Measuring service quality: a comparative assessment based on customer service of HSBC and DBBL." Journal of Banking \& Financial Services 5.1 (2011), pp.111127.

[26] Ladhari, Riadh, Ines Ladhari, and Miguel Morales. "Bank service quality: comparing Canadian and Tunisian customer perceptions." International Journal of Bank Marketing (2011).

[27] Megeid, Nevine Sobhy Abdel. "The impact of service quality on financial performance and corporate social responsibility: Conventional versus Islamic banks in Egypt." International Journal of Finance and Accounting 2.3 (2013), pp.150-163.

[28] McKinney, Vicki, Kanghyun Yoon, and Fatemeh "Mariam Zahedi. "The measurement of web-customer satisfaction: An expectation and disconfirmation approach." Information systems research 13.3 (2002), pp. 296-315.

[29] Hair Jr, Joseph F., et al. A primer on partial least squares structural equation modeling (PLS-SEM). Sage publications, 2016.

[30] Palmer, Jonathan W. "Web site usability, design, and performance metrics." Information systems research 13.2 (2002), pp.151-167.

[31] Teo, Hock-Hai, et al. "An empirical study of the effects of interactivity on web user attitude." International journal of human-computer studies 58.3 (2003), pp. 281-305.

[32] Janda, Swinder, Philip J. Trocchia, and Kevin P. Gwinner. "Consumer perceptions of Internet retail service quality." International journal of service industry management (2002).

[33] Hair, Joseph F., et al. "Multivariate data analysis: A global perspective (Vol. 7)." (2010).

[34] Kline, Rex B. Principles and practice of structural equation modeling. Guilford publications, 2015.

[35] Mohammed Alhendawi, K. A. M. A. L., and A. H. M. A. D. Suhaimi Baharudin. "The assessment of information system effectiveness in elearning, e-commerce and egovernment contexts: a critical review of the literature." Journal of Theoretical \& Applied Information Technology 95.18 (2017).

[36] Alhendawi, Kamal Mohammed, and Ala Aldeen Al-Janabi. "An intelligent expert system for management information system failure 
diagnosis." International Conference on Intelligent Computing \& Optimization. Springer, Cham, 2018.

[37] Petter, Stacie, William DeLone, and Ephraim McLean. "Measuring information systems success: models, dimensions, measures, and interrelationships." European journal of information systems 17.3 (2008), pp. 236-263.
[38] DeLone, William H., and Ephraim R. McLean. "The DeLone and McLean model of information systems success: a ten-year update." Journal of management information systems 19.4 (2003), pp.9-30.

[39] Alhendawi, Kamal Mohammed. "Predicting the effectiveness of web information systems using neural networks modeling: framework \& empirical testing." International Journal of Software Engineering and Computer Systems (IJSECS) 4.1 (2018): 61-74. 